\title{
Non-smoking policies, tobacco education, and smoking cessation programmes in facilities serving the elderly in Michigan, United States
}

\author{
James A Bergman, Judith L Falit
}

\begin{abstract}
Objective-To determine the extent of and impetus for smoke-free policies in facilities serving Michigan's elderly, and the extent of tobacco education and smoking cessation programmes for elders and staff of these facilities.
\end{abstract}

Design-Telephone survey in February 1997 of three types of facilities serving Michigan's elderly population.

Subjects-Area Agencies on Aging ( $\mathrm{n}=$ 12), Councils and Commissions on Aging $(n=31)$, and senior centres $(n=98)$ located in Michigan, USA.

Main outcome measures-Prevalence of smoke-free policies, tobacco education, and smoking cessation programmes in facilities serving the elderly.

Results-99\% (95\% confidence interval (CI) $=97 \%$ to $100 \%$ ) of 141 facilities surveyed have an indoor smoke-free policy. Eighty-five per cent $(95 \% \mathrm{CI}=79 \%$ to $91 \%$ ) of these policies prohibit all smoking inside the facility. Forty-five per cent $(95 \% \mathrm{CI}=37 \%$ to $54 \%)$ cited a law as requiring the smoke-free policy, whereas $38 \%(95 \%$ CI $=30 \%$ to $46 \%)$ indicated the policy was adopted voluntarily for health reasons. Forty-two per cent $(95 \% \mathrm{CI}=34 \%$ to $50 \%$ ) of the facilities provided some education on the dangers of tobacco, while $11 \%(95 \%$ CI $=6 \%$ to $16 \%)$ arranged smoking cessation programmes for staff or elders.

Conclusions-In Michigan, a very high percentage of non-institutional facilities serving the elderly have smoke-free policies, which appear to increase participation at these facilities. Tobacco education programmes are provided in less than half the facilities, and very few arrange smoking cessation programmes for elders or staff.

(Tobacco Control 1997;6:194-198)

Keywords: smoking policy; smoking cessation programmes; tobacco education; elderly

The Center for Social Gerontology, Inc., Ann Arbor, Michigan, USA J A Bergman

J L Falit

Correspondence to: JA Bergman, The Center fo Social Gerontology, Inc. 2307 Shelby Avenue, Ann Arbor, Michigan 48103, USA; email: tcsg@izzy.net

\section{Introduction}

Tobacco use is a geriatric disease in the United States. Of almost 416000 deaths annually in the United States due to smoking, more than $70 \%$ occurred in people aged 65 and older, and more than $94 \%$ in those aged 50 and older. ${ }^{1}$ Thus, although smoking rates among those aged 65 and older are the lowest of all adult cohorts- $-12 \%$ among those aged 65 and older as of 1994 , versus approximately $27 \%$ for all adults aged 18 to 64 -the disease, suffering, and death caused by smoking overwhelmingly occurs among older people, and this will continue well into the 21 st century based on current smoking and mortality rates. ${ }^{2}$

More than 53000 Americans-mainly middle-aged and older - who never smoked die each year of diseases caused by environmental tobacco smoke (ETS), principally of cancer, heart and lung disease. ${ }^{3}$ Millions of other nonsmoking older Americans suffer from ETS, particularly those with pre-existing heart or respiratory diseases. ${ }^{4}$

Recent studies have shown that some of the health benefits of quitting smoking are almost immediate for the elderly, as well as for the young. Even for those people over 50, quitting smoking can avoid or delay illnesses that could drastically affect the length and quality of life..$^{5-8}$

These data clearly demonstrate the need for smoke-free policies in facilities frequented by older people, and the need for tobacco education and smoking cessation programmes targeted at the elderly. However, there have been few studies on the prevalence of smoke-free policies in facilities specifically serving the elderly, or on the extent of tobacco education or smoking cessation programmes implemented when smoke-free policies were adopted in facilities serving the elderly. ${ }^{912}$ This study provides a preliminary assessment of the nature and scope of smoke-free policies and related tobacco education and smoking cessation programmes in non-institutional facilities serving older people.

\section{Methods}

SUBJECTS

Survey data were collected from the three major non-institutional types of facilities serving Michigan's elders: Area Agencies on Aging (AAAs), Michigan Councils and Commissions on Aging (MCCAs), and senior centres. All three types of facilities are also worksites for staff serving elders. AAAs are public or private non-profit agencies which are focal points for elder rights advocacy, provide information and casework services for elders, and fund other local aging services programmes in their geographical area. ${ }^{13}$ MCCAs and senior centres are the primary community facilities providing meals, and social and recreational programmes for the elderly. MCCAs are public agencies of county governments, whereas senior centres are local 
public or private facilities, which provide social and recreational activities and also serve as nutrition sites, generally serving one meal a day to their clientele. For the purposes of this survey, stand-alone nutrition sites, stand-alone senior centres, and combined nutrition sites and senior centres are all categorised as senior centres.

As there are only 16 AAAs and 56 MCCAs in Michigan, all Michigan AAAs and MCCAs were included in the telephone survey. In contrast, there are 459 senior centres in Michigan. ${ }^{14}$ The costs and time required to survey by phone all 459 senior centres would have been prohibitive; therefore, random sampling was used to obtain a representative group of 161 Michigan senior centres for this telephone survey. A listing of the 459 senior centres in Michigan, arranged by zip code, was obtained from the Michigan senior resource directory, 1995. Every third senior centre from this listing was included in the survey; the starting point was randomly selected.

Interviewers telephoned 16 AAAs, 52 MCCAs, and 161 senior centres and asked to speak to the director or manager of the organisation; if this person was unavailable, interviewers called again at a different time. In all, six AAAs, 15 MCCAs, and 27 senior centres were called back at least once. Respondents were limited to directors and managers as they were assumed to have the most knowledge of smoke-free policies implemented in their organisations.

\section{DESIGN}

Data in this survey were collected through a telephone survey conducted by staff from The Center for Social Gerontology (Ann Arbor, Michigan) during the first three weeks of February 1997 . The survey consisted of 10 closedended questions, two open-ended questions, and an opportunity for respondents to elaborate on their responses throughout. On average, the interview lasted two to three minutes. Respondents were informed that this was a survey regarding smoke-free policies in organisations serving the elderly in Michigan and that their individual responses would remain confidential.

The questions in the survey were based on those in a mail survey on smoking policies included in the Summer 1996 issue of Tobacco $\mathcal{E}$ the Elderly Notes, which was sent to all 459 senior centres in Michigan and all 56 MCCAs.
(Tobacco $\mathcal{E}$ the Elderly Notes is a quarterly newsletter published by The Cent for Social Gerontology (TCSG). The pulfication is distributed to more than 1300 senfor centres, AAAs, MCCAs, healthcare facilities, other organisations serving the elderly, atd tobacco control organisations in Michigigan and throughout the United States. The survey sent with the Summer issue assessed types of smoke-free policies and related tob Jcco educa- $^{\circ}$ tion and smoking cessation programmes that existed in facilities serving the welderly in Michigan. From the 1000 surveys initially mailed, TCSG received 99 respônses. The findings largely concurred with the of the telephone survey discussed in this aticle; $95 \%$ (94) indicated that they had an ind8or smokefree policy; of those with smoke-free policies, $84 \%$ (79) did not permit smoking $\$$ any area of their facilities.)

윽

The questions in the survey reported here were adapted only to facilitat $\$$ it being conducted by telephone; efforts we made to ensure that differences in wording $\mathbb{D}$ ere minor and did not affect the moganing or interpretation of the questions.

Respondents were first asked if $\overrightarrow{\text { eir facility }}$ had an indoor smoke-free policy (see table 1 for definitions of types of smoke-frge policies); those that answered in the affirmative ( $\mathrm{n}=$ 139) continued with the survey rep⿳亠丷厂巾ted in this article. Those respondents who in \$్tcated that their organisation did not have an indoor smoke-free policy $(\mathrm{n}=2)$ wer $\overrightarrow{\vec{\varepsilon}}$ asked a different set of questions, the detais of which are beyond the scope of this article

In addition to discussing the extent of their facility's indoor smoke-free policy, rôspondents were asked to identify the impetung for their smoke-free policy as well as to indicẩe whether they provided education on the offects of tobacco or arranged for a smoking cessation programme. Respondents were ${ }_{\text {asked to }}$

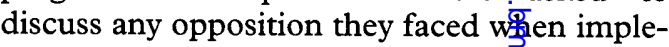
menting the smoke-free policy and to assess the consequences of the policy on the elders' use of the facility.

\section{RESPONSE RATES}

음

Of the 229 organisations selected for the telephone survey, 34 had disonnected telephone numbers. From the remaining 195 eligible organisations, a total of 141 Noesponded to the survey, for an overall respogyse rate of $72.3 \%$. Respondent organisations iucluded 12

Table 1 Types of smoke-free policies

\begin{tabular}{|c|c|c|c|c|c|c|c|c|}
\hline Policy & $\begin{array}{l}\text { All } \\
(\%)(n=139)\end{array}$ & $95 \% C I$ & $\begin{array}{l}A A A s \\
(\%)(n=12)\end{array}$ & $95 \% C I$ & $\begin{array}{l}M C C A s \\
(\%)(n=31)\end{array}$ & $95 \% C I$ & $\begin{array}{l}\text { Senior centros } \\
(\%)\left(n=\frac{\mathbb{Q}}{\mathbb{D}}\right)\end{array}$ & $95 \% C I$ \\
\hline $\begin{array}{l}\text { Smoking is not permitted in any area of the } \\
\text { programme facility }\end{array}$ & 85 & $79-91$ & 100 & $76-100$ & 87 & $75-99$ & 82 蛋 & $75-90$ \\
\hline $\begin{array}{l}\text { Smoking is permitted only in a designated } \\
\text { area/room which is separated from all other }\end{array}$ & & & & & 01 & $13-99$ & $\tilde{\sigma}$ & $13-90$ \\
\hline areas & 10 & $5-15$ & 0 & $0-24$ & 10 & $0-20$ & 8 & $5-18$ \\
\hline $\begin{array}{l}\text { Smoking is permitted only in a designated } \\
\text { area/room which is not separated from }\end{array}$ & & & & & & & 흐. & \\
\hline $\begin{array}{l}\text { non-smoking areas. } \\
\text { Smoking is permitted only at designated times }\end{array}$ & 2 & $0-7$ & 0 & $0-24$ & 0 & $0-10$ & $\stackrel{0}{\text { D }}$ & $0-7$ \\
\hline $\begin{array}{l}\text { Smoking is permitted only at designated times. } \\
\text { Other }\end{array}$ & 2 & $0-7$ & 0 & $0-24$ & 3 & $0-9$ & 2 & $0-5$ \\
\hline & 1 & $0-7$ & 0 & $0-24$ & 0 & $0-10$ & 1 & $0-3$ \\
\hline
\end{tabular}

Differences across organisation types not significant $(P>0.05)$.

AAAS = Area Agencies on Aging; MCCAs = Michigan Councils and Commissions on Aging

$\mathrm{CI}=$ confidence intervals. 
AAAs (75\%), 31 MCCAs (72\%), and 98 senior centres $(72 \%)$. Of the remaining 54 organisations, interviewers were unable to reach them; there were no refusals to participate. Although this non-response affected the final sample size, there was no known opportunity for self-selection.

Twenty-seven organisations that had responded to the earlier, mailed survey were among the 229 randomly selected for the telephone survey. Follow-up calls were made to 21 of these organisations to clarify ambiguous or incomplete responses; the remaining six organisations had completed the mailed survey in full. As the data from the mailed survey were received in the Autumn of 1996, and the questions were identical to those in the telephone survey, these respondents were not surveyed again. Differences between mailed and telephone survey respondents were not significant $(P>0.05)$ for all questions except for two addressing changes in attendance as a result of the smoke-free policy $(P \leqslant 0.032)$.

\section{Results}

SMOKE-FREE POLICIES

Of the 141 AAAs, MCCAs, and senior centres who responded to the survey, $99 \%(95 \% \mathrm{CI}=$ $97 \%$ to $100 \%$ ) had some form of indoor smoke-free policy. Further, of the 139 organisations with smoke-free policies, $85 \%$ $(95 \%$ CI $=79 \%$ to $91 \%)$ required that the facility be completely smoke-free. In only $5 \%$ $(95 \% \mathrm{CI}=2 \%$ to $9 \%)$ of the facilities with smoke-free policies was smoking permitted in areas that were not physically separated from smoke-free areas (table 1).

There was no significant relationship between the type of facility and whether a smoke-free policy had been implemented $(P>0.05)$. Of the 141 facilities interviewed, only two of 98 senior centres lacked a smoke-free policy of some type, whereas all AAAs and MCCAs interviewed had some smoke-free policy.

IMPETUS FOR SMOKE-FREE POLICIES

Of the 139 respondents with some form of smoke-free policy, $45 \%$ (95\% CI $=37 \%$ to $54 \%$ ) stated that their facility had an indoor smoke-free policy due to state, city, or county law. (Respondents were asked to distinguish whether state/federal law or city/town/county law required the smoke-free policy. Of the 139 respondents, $22(15.8 \%)$ indicated the policy was implemented to be in compliance with a state law; $40(28.8 \%)$ indicated the policy was for compliance with a city, town, or county law; one $(0.7 \%)$ indicated that the smoke-free policy was due to both state and city laws. However, because the respondents in a number of cases seemed unclear whether the smoke-free policy was due to state or local law, we were uncertain whether the respondents were able to identify accurately which law was the true impetus for their indoor smoke-free policy. Therefore, for purposes of this analysis, we have grouped together those respondents who indicated the impetus as either a federal, state, city, county, or town law.)
Although responses varied by organisational type, the differences were not statistically significant $(\mathrm{P}>0.05)$. Thirty-eight per cent $(95 \% \mathrm{CI}=30 \%$ to $46 \%)$ of respondents that have smoke-free policies said their policy was implemented voluntarily, generally due to health concerns. The remaining $17 \%$ (95\% CI $=10 \%$ to $23 \%$ ) of respondents stated they did not know why the smoke-free policy had been implemented or indicated "other" reasons for their smoke-free policy.

OPPOSITION TO SMOKE-FREE POLICIES

Of the 139 respondents with smoke-free policies, $62 \%(95 \%$ CI $=54 \%$ to $70 \%)$ reported no opposition to the smoke-free policies. Of the $38 \%(95 \% \mathrm{CI}=30 \%$ to $46 \%)$ of respondents who reported opposition to the smoke-free policies, an overwhelming majority stated that the number of elders, staff, or members of the public who opposed the policy was insignificant-generally just one or two persons objected, and the objection had virtually no effect on these individuals' participation in the facilities' activities.

Among the 53 organisations that did report opposition, $80 \%$ ( $95 \%$ CI $=68 \%$ to $90 \%)$ indicated that elders who used the facility were the source of opposition, whereas objections from staff were reported by respondents in $40 \%(95 \% \mathrm{CI}=26 \%$ to $53 \%)$ of the facilities (Note that some respondents reported opposition to the policies from both elders and staff.)

EFFECTS ON ATTENDANCE ATTRIBUTED TO SMOKE-FREE POLICIES

Respondents in $72 \%$ (95\% CI $=64 \%$ to $79 \%$ ) of the facilities surveyed stated that no elders stopped using the facility as a result of the smoke-free policy. Twelve per cent $(95 \% \mathrm{CI}=$ $7 \%$ to $18 \%$ ) stated that "a few" elders - meaning one or two persons - stopped using the facility. Only 1\% (95\% CI = 0\% to $3 \%$ ) reported "some" elders (three or four) stopped using the facilities, and just one facility reported that "a lot" of elders (five or more) stopped attending.

Six per cent $(95 \% \mathrm{CI}=2 \%$ to $10 \%)$ of the respondents said that "a lot" of elders started attending, and $7 \%(95 \% \mathrm{CI}=3 \%$ to $12 \%)$ stated that "some" new elders began participating due to the smoke-free policies. In addition, $12 \%(95 \% \quad \mathrm{CI}=6 \%$ to $17 \%)$ reported that the smoke-free policies resulted in "a few" new elders attending facility activities. Fifty-six per cent $(95 \% \mathrm{CI}=48 \%$ to $64 \%$ ) of respondents reported no changes in attendance due to the smoke-free policies; and about $14 \%(95 \% \mathrm{CI}=8 \%$ to $19 \%)$ were not certain of the effects.

EDUCATION ON EFFECTS OF TOBACCO

Although an overwhelming number of facilities for the elderly have implemented smoke-free policies, only $42 \%$ ( $95 \% \mathrm{CI}=34 \%$ to $50 \%$ ) of the organisations indicated that they provided some type of education on the effects of tobacco and smoking (table 2). Differences in the provision of tobacco education among the 


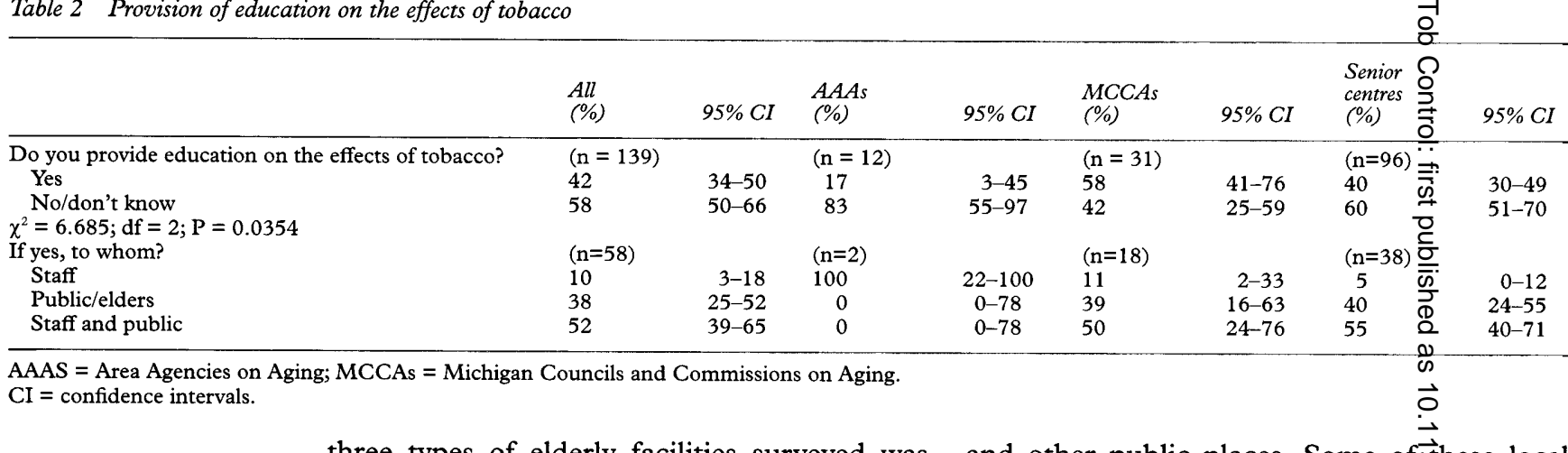

three types of elderly facilities surveyed was significant $\left(\chi^{2}=6.685, \mathrm{df}=2, \mathrm{P}=0.035\right)$.

SMOKING CESSATION PROGRAMMES

Just $11 \%$ (95\% CI $=6 \%$ to $16 \%)$ of the facilities with smoke-free policies provided or arranged for smoking cessation programmes for their staff or elderly clientele. Although differences between organisations were not significant $(P>0.05)$, none of the 12 AAAs surveyed had arranged a smoking cessation programme for their employees.

\section{Discussion}

This study of smoking and the elderly sought to obtain preliminary data, and several limitations are important to note. The study relied upon self-reported perceptions of the respondents, not upon data such as programme or attendance records or actual copies of smoke-free policies. The survey also did not address the issues of enforcement; it is possible that, although smoke-free policies are in place, staff and elders do not comply with the regulations. Similarly, the survey sought to determine the extent of smoking cessation programmes; it did not seek to determine successful cessation rates for staff and elders participating in the programmes. Finally, the study obtained information only from facilities in Michigan; thus, it is unknown how generalisable our results may be to similar facilities in other states.

We recognised that the Michigan Clean Indoor Air Act ${ }^{15}$ and local clean indoor air laws set the state apart from some others in terms of smoke-free policies. The study, therefore, sought to make a threshold assessment of the impact of these laws on the adoption of smokefree policies in elderly facilities, albeit without conducting a study of smoke-free policies before and after the adoption of the statewide law in 1986 and subsequent local laws. The statewide law prohibits smoking in certain facilities-including facilities owned by state or local governments and various health care facilities-except in designated areas. The designated areas for smoking in these facilities may be adjacent to non-smoking areas and are not required to be separately enclosed and ventilated. Thus, the state law does not require completely smoke-free facilities, except in certain areas of healthcare or childcare facilities.

Many cities, towns, and counties in Michigan have enacted their own clean indoor air laws covering county or municipal buildings and other public places. Some of $\overrightarrow{\vec{c}}$ hese local laws require completely smoke-fre and a number of the senior contres and MCCAs in the state are located in.such buildings. Therefore, some of the facilitirveyed were covered by both local and state clean indoor air laws. However, since Michigan's clean indoor air laws do not cover most private-sector worksites and office $\$$ uildingswhere many AAAs and some seniorscentres are located-facilities for the eldefy located therein are not required by 吕w to be smoke-free.

Within these parameters, one of the key findings of this study is that most of the surveyed non-institutional facilities serving the elderly in Michigan had som type of smoke-free policies (more than $98 \%$, and $84 \%$ had policies that prohibited all smơking in the facility.

The Michigan Clean Indoor A local clean indoor air laws appear to have been a significant impetus for this high pexicentage of smoke-free policies, with $45 \%$ of the respondents citing these laws as the basis for their policies. Another $38 \%$ of $\frac{\hat{R}}{\mathrm{R}}$ spondents stated that their smoke-free poficies were adopted voluntarily due to healtt店 concerns; responses to open-ended survey questions indicated that these voluntarile enacted policies were in reaction to the Realth risks posed by smoking and environmen smoke (ETS), including fire hazards. Although the survey did not seek to determineany correlation between the existence of the clean indoor air laws and the voluntary gloption of smoke-free policies by facilities that were not covered by these laws, such a side effect is plausible.

Additional research is needed in ${ }^{\sigma}$ ther states to determine the prevalence of and $\bar{m}$ metus for the adoption of smoke-free plicies by non-institutional elderly facilities, particularly in states that lack clean indoor air Bâns or that have a tradition of opposing $\frac{\mathbb{Q}}{\mathbb{Q}}$ moke-free
policies.

A finding of special interest to elderly service providers is that smoke-free poliges engendered minimal opposition by elders $8 \mathrm{r}$ staff and had a positive effect on attendance by elders at activities in these facilities. Both the data and anecdotal comments indicated that the increased participation due to the smoke-free policies more than offset any loss of attendance. These findings suggest that 
smoke-free policies are good health policy and also good outreach strategy.

A somewhat disturbing finding was the low level of preventive health education on the dangers of tobacco use and ETS. Just $40 \%$ of the facilities surveyed stated that they provided some type of education on the effects of tobacco or ETS, or both, and half of these used handout materials, pamphlets or brochures, which are the most passive form of health education. Fewer than a third of the facilities that provided education on the risks of tobacco used speakers or more interactive methods. Reflecting the data findings, several respondents said: "There is no need for education on the effects of tobacco since, by the time you are an elder, you already know that it is bad for you."

An even more disturbing finding was the low level of availability of smoking cessation programmes in the facilities surveyed. Only $11 \%$ reported that they provided or arranged for smoking cessation programmes for either elders or staff using their facility. Few respondents addressed the issue of providing smoking cessation programmes for staff, suggesting that such worksite cessation programmes were rarely considered.

Several respondents from all three types of the surveyed facilities stated that "there is no need for smoking cessation programmes for the elders since there are not that many left smoking, just a few 'die-hards' who are already 90 years old and will never quit." Most respondents claimed that older smokers were not interested in cessation programmes. However, this view is contradicted by a 1994 Cancer supplement paper stating: "Results from the Clear Horizons trial show that older smokers are interested in quitting and will respond positively to a programme tailored to their needs." ${ }^{2}$ And a recent $\not A M A$ article emphasised that: "Age was also a significant independent predictor of success-older persons were more likely than younger persons to quit successfully." 16

Recent research suggests that implementation of smoke-free policies in worksites can itself be an event that triggers smokers to try to quit, and therefore is an excellent time for facilities to arrange for smoking cessation programmes. ${ }^{17}{ }^{18}$ Thus, elderly facilities implementing smoke-free policies are currently missing a significant opportunity to offer smoking cessation programmes for both elders and staff.

\section{Conclusion}

As former US Secretary of Health, Education, and Welfare Joseph Califano has pointed out, the current crisis in the funding of the Medicare programme could have largely been avoided if substance abuse prevention programmes, particularly on the dangers of tobacco, had been implemented. ${ }^{19}$ Ignoring the elderly population in these efforts ignores the realities that the fastest growing segment of American society is the $65+$ population, and that tobacco prevention efforts can succeed with the elderly as much as with the young.

1 US Department of Health and Human Services. SAMMEC 3.0. Smoking-attributable mortality, morbidity, and economic costs. Rockville, Maryland: Centers for Disease Control and Prevention, Office on Smoking and Health, 1996.

2 US Centers for Disease Control and Prevention. Cigarette smoking among adults-United States, 1994. MMWR 1996;45:588-90.

3 Glantz SA, Parmley WW. Passive smoking and heart disease: epidemiology, physiology, and biochemistry. Circulation 1991;83:1-12.

4 US Environmental Protection Agency. Respiratory health effects of passive smoking: lung cancer and other disorders. 1992:5-68. (EPA/600/6-90/006F.)

5 Levitt S. It's never too late to stop smoking. New Choices for the Best Years 1990;30:69-72.

6 US Department of Health and Human Services. The health benefits of smoking cessation. A report of the Surgeon General, 1990. Rockville, Maryland: Public Health Service, Centers for Disease Control, Office on Smoking and Health, 1990 (DHHS Publication No (CDC) 90-8416.)

7 Rogers RL, Meyer JS, Judd BW, Mortel KF. Abstention from cigarette smoking improves cerebral perfusion among elderly chronic smokers. $¥ A M A$ 1985;253:2970-4

8 Anon. Smoking cessation offers significant benefits for older adults. Geriatrics 1992;47(5):91.

9 Kochersberger G, Clipp EC. Resident smoking in long-term care facilities-policies and ethics. Public Health Rep 1996; 111:66-70.

10 Barker JC, Mitteness LS, Wolfsen CR. Smoking and adulthood: risky business in a nursing home. $\mathcal{F}$ Aging Stud 1994;8:309-26.

11 Parks JJ, Devine DD. The effects of smoking bans on extended care units at state psychiatric hospitals. Hosp Commun Psychiatry 1993;44:885-6.

12 Rimer BK, Orleans CT. Tailoring smoking cessation for older adults. Cancer 1994;74(suppl):2051-4.

13 National Association of Area Agencies on Aging. National directory for eldercare information and referral, 1996-1997. Washingto DC: National Association of Area Agencies on Aging.

14 Michigan Office of Services to the Aging. Michigan senior resource directory, 1995. Lansing: Michigan Office of Services to the Aging.

15 Mich Comp Laws Ann of 333.12601-17 (West 1992). Enacted in 1986 and amended subsequently.

16 Fiore MC, Novotny TE, Pierce JP, et al. Methods used to quit smoking in the United States. $¥ A M A$ 1990;263:2760-

17 Woodruff TJ, Rosbrook B, Pierce J, Glantz SA. Lower levels of cigarette consumption found in smoke-free workplaces in California. Arch Intern Med 1993;153:1485-93.

18 Hudzinski LG, Sirois PA. Changes in smoking behavior and body weight after implementation of a no-smoking policy in the workplace. Southern Med $71994 ; 87: 322-7$.

19 Center on Addiction and Substance Abuse. The cost of sub stance abuse to America's health care system - report 2: Medicare hospital costs 1. New York: Columbia University, 1994 